\title{
SISTEM PAKAR MENENTUKAN FASHION STYLE BERDASARKAN KRITERIA FISIK DENGAN METODE CERTAINTY FACTOR BERBASIS WEB
}

\author{
Bananudin $^{1}$, Vidila Rosalina ${ }^{2}$ \\ ${ }^{1,2}$ Program Studi Teknik Informatika Fakultas Teknologi Informasi Universitas Serang Raya \\ Jln. Raya Cilegon Serang - Drangong Kota Serang \\ ${ }^{1}$ bananudin29@gmail.com \\ 2vidila.suhendarsah@gmail.com
}

\begin{abstract}
Abstrak - Fashion style merupakan hal penting dalam berpenampilan agar penampilan seseorang terlihat lebih menarik. Sehingga hampir setiap orang membutuhkan pengetahuan jenis fashion yang sesuai dengan kriteria fisiknya, tapi masih banyak masyarakat khususnya perempuan tidak mengetahui fashion style apa yang sesuai dengan kriteria fisiknya. Sistem Pakar ini diperlukan untuk menentukan style fashion berdasarkan kriteria fisik menggunakan metode Certainty Factor. Metode CF ini dipilih karena memiliki tingkat keakuratan yang cukup tinggi. Sistem pakar fashion style ini dirancang menggunakan UML (Unified Modeling Language) yang terdiri dari 4 diagram yaitu use case diagram, sequence diagram, activity diagram, dan class diagram. Program aplikasi fashion style ini dibangun menggunakan bahasa pemrograman PHP, HTML, Java, dan untuk design interfacenya mengunakan CSS. Database yang digunakan dalam program aplikasi fashion style adalah MySQL. Aplikasi fashion style telah diuji menggunakan metode pengujian blackbox. Dari hasil aplikasi yang dibangun diharapkan dapat memermudah pengguna untuk memilih dan menentukan fashion style yang sesuai untuk kriteria fisiknya.
\end{abstract}

Kata kunci : CF, Fashion Style, Sistem Pakar, Kriteria Fisik, Web.

\section{PENDAhUluan}

Perkembangan fashion style sangatlah cepat seiring dengan berkembangnya teknologi, hampir setiap tahun dan setiap bulan bahkan setiap harinya muncul produk fashion style dengan model baru yang diciptakan oleh para desainer. Hal ini dapat mempengaruhi masyarakat khususnya perempuan untuk mengikuti dan membeli produk fashion style yang sedang trending tersebut. Namun, tidak semua perempuan mengetahui atau memperhatikan tentang fashion style yang sedang trending tersebut apakah sesuai dengan kriteria fisiknya atau tidak. Beradasarkan informasi yang didapatkan melalui studi literatur dan jelajah internet sistem informasi tentang fashion style yang sesuai dengan kriteria fisik tidak begitu banyak ditemukan. Sedangkan target pengguna sistem yang disasar adalah seorang desainer fashion dan perempuan berusia 18-30 tahun yang membutuhkan pengetahuan dan rekomendasi tentang fashion style yang sesuai dengan kriteria fisiknya. Dengan adanya aplikasi untuk menentukan fashion style berdasarkan kriteria fisik yang berbasis website setiap orang dapat mengetahui jenis-jenis produk fashion style yang sesuai dengan kriteria fisiknya.

Berdasarkan latar belakang yang telah diuraikan diatas, dapat diambil rumusan masalah sebagai berikut bagaimana menganalisis, merancang dan membangun sistem pakar untuk menentukan fashion style berdasarkan kriteria fisik dengan metode certainty factor berbasis web?

Tujuan penelitian ini untuk membangun sistem pakar penentuan fashion style berdasarkan kriteria fisik seseorang agar tidak salah dalam memilih dan membeli pakaian. Sistem pakar ini juga diharapkan dapat memberikan manfaat kepada masyarakat agar berpenampilan baik dan sesuai.

\section{Metodologi Penelitian}

Menurut Sari Iswanti (2018:57), Pengertian sistem pakar menurut Martin dan Oxman dalam buku Sistem Pakar dan Pengembangannya [7] adalah sistem berbasis komputer yang menggunakan pengetahuan, fakta, dan teknik penalaran yang dimasukkan ke dalam komputer untuk menyelesaikan masalah 
yang biasanya diselesaikan oleh seorang pakar. Pengetahuan adalah pemhaman secara teori maupun praktik suatu obyek dalam domain tertentu. Sumber pengetahuan diperoleh dari berbagai sumber keahlian seperti pakar, jurnal dan artikel ilmiah, buku, jurnal ilmiah atau dokumentasi dengan berbagai media.

Sistem pakar masih menyisakan suatu persoalan yaitu ketidakpastian. Ketidakpastian dapat diartikan sebagai kurangnya informasi untuk mengambil keputusan. Ketidakpastian pada pengetahuan diatasi dengan adanya tingkat kepastian pada gejala, kaidah, dan hasil identifikasi Salah satu cara untuk mengatasi ketidakpastian adalah dengan menggunakan metode Certainty Factor (CF). Pengetahuan yang dimasukkan ke dalam sistem pakar, salah satunya adalah kaidah/aturan. Representasi kaidah dapat disajikan menggunakan kaidah produksi yaitu IF E THEN H. Notasi E menunjukkan evidence (gejala) dan $\mathrm{H}$ adalah hipotesa. Bentuk dasar rumus certainty factor sebuah aturan dalam bentuk IF E THEN H adalah sebagai berikut (Giarattano dan Riley, 2005)[6].

Gaya atau style bersifat personal. Jadi, berbeda orangnya, berbeda pula cara berpakaiannya. Pakaian itu sendiri memiliki jenis yang bermacam macam, seperti atasan, bawahan, aksesoris, dan lain-lain. Setiap jenis pakaian tersebut memiliki pembagian menjadi berbagai macam bentuk yang sengaja diciptakan menyesuaikan bentuk tubuh atau tujuan dari jenis pakaian tersebut.

Hal di atas diangkat sebagai tema perancangan karena tidak semua orang mengetahui apa saja jenis-jenis pakaian yang ada, dan pakaian mana yang cocok untuk kegiatan tertentu. Hal tersebut terkadang menyebabkan orang-orang tidak percaya diri dengan apa yang dipakainya dan merasa salah kostum [1].

Kriteria atau ciri-ciri fisik berhubungan dengan sifat yang dibawa oleh ras seperti bentuk dan warna rambut, postur tubuh, warna mata, dan lain sebagainya.

Somatoskopi merupakan sebuah metode untuk melihat ciri-ciri fisik manusia, baik secara keseluruhan atau bagianbagian tertentu saja. Observasi secara somatoskopi dianggap sangat penting untuk dilakukan, mengingat deskripsi ini memberikan kesan umum pertama saat menggambarkan orang lain. Observasi pada somatoskopi menyangkut tiga hal penting antara lain, pigmentasi, bentuk, dan proporsi. Pigmentasi dalam metode somatoskopi meliputi warna kulit, warna rambut, dan warus iris mata. Berbagai bentuk-bentuk rambut, dahi, mata, hidung, bibir, dan wajah, juga merupakan hal terpenting dalam metode somatoskopi. Aspek ketiga dalam somatoskopi adalah proporsi, yang di mana proporsi tubuh dapat berhubungan dengan konstitusi badan, pembagian ras, dan perubahan ontogenesis (Glinka, et al., 2007, p. 49) [7].
Certainty factor merupakan suatu metode yang digunakan untuk memecahkan permasalahan dari jawaban yang tidak pasti, dan menghasilkan jawaban yang tidak pasti pula. Ketidak pastian ini dipengaruhi oleh dua faktor yaitu aturan yang tidak pasti dan jawaban pengguna yang tidak pasti.

Metode certainty factor digunakan ketika menghadapi suatu masalah yang jawabannya tidak pasti. Ketidakpastian ini bisa merupakan probabilitas. Metode ini diperkenalkan oleh Shortlife Buchanan pada tahun 1970-an [2].

Website adalah kumpulan dari berbagai macam halaman situs, yang terangkum di dalam sebuah domain atau juga subdomain, yang lebih tempatnya berada di dalam $W W W$ (World Wide Web) yang tentunya terdapat di dalam Internet.

"Web adalah salah satu aplikasi yang berisikan dokumendokumen multimedia (teks, gambar, suara, animasi, video) di dalamnya yang mengunakan protokol HTTP (hypertext transfer protokol) dan untuk mengakses menggunakan perangkat lunak yang disebut browser" [4].

\section{HASIL DAN PEMBAHASAN}

\subsection{Teknik Pengumpulan Data}

Pengumpulan data, kegiatan ini untuk mengoleksi data penelitian dari berbagai sumber, berupa data kriteria fisik dan fashion style seseorang. Metode pengumpulan data yang digunakan dalam penelitian ini adalah sebagai berikut:

a. Studi Literatur

Pengumpulan data dengan cara literatur, jurnal, paper dan bacaan-bacaan yang berkaitan dengan judul penelitian.

\section{b. Observasi}

Teknik pengumpulan data dengan mengadakan penelitian dan peninjauan langsung terhadap permasalahan yang stabil.

c. Wawancara

Teknik pengumpulan data dengan mengadakan tanya jawab secara langsung yang ada kaitannya dengan penelitian yang diambil.

\subsection{Teknik Pengembangan Sistem Pakar}

Teknik pengembangan software dalam penelitian ini yang digunakan adalah waterfall, adapun tahapan-tahapan waterfall sebagai berikut:

1. Analisis Sistem

Tahap ini dilakukan analisis hasil pengumpulan data yang telah diambil dengan cara studi literatur, observasi dan wawancara pada objek penelitian untuk mengetahui kebutuhan-kebutuhan yang diperlukan dalam aplikasi.

2. Perancangan Sistem

Tahapan ini merupakan tahapan perancangan dan desain aplikasi menentukan fashion style berdasarkan kriteria fisik yang dikembangkan yaitu dengan membuat input, proses, output dan database. 
3. Pembuatan Software

Tahap ini adalah proses membangun aplikasi fashion style berdasarkan kriteria fisik dengan menggunakan framework berbasis PHP (Hypertext Preprocessor) yang mampu digunakan untuk membuat aplikasi berskala besar berbasis web, dengan menggunakan MySQL sebagai database penyimpanan datanya.

4. Pengujian Software

Tahap ini dilakukan pengujian untuk mengetahui apakah aplikasi sesuai dengan yang diharapkan dan testing aplikasi yang digunakan pada analisis ini menggunakan Black Box Testing.

5. Implementasi dan Pemeliharaan

Tahap ini, software yang telah dibuat dan melewati tahap pengujian akan diimplementasikan (diluncurkan) pada website agar dapat digunakan oleh user atau pengguna internet. Dan jika software mengalami masalah atau error maka akan dilakukan pemeliharaan untuk memperbaiki masalah atau error yang tidak ditemukan pada langkah sebelumnya.

\subsection{Analisis Sistem Yang Berjalan}

Menjelaskan mengenai sistem pakar yang sedang berjalan pada objek penelitian yang sesuai dengan tema penelitian, seperti pada Gambar 3.1

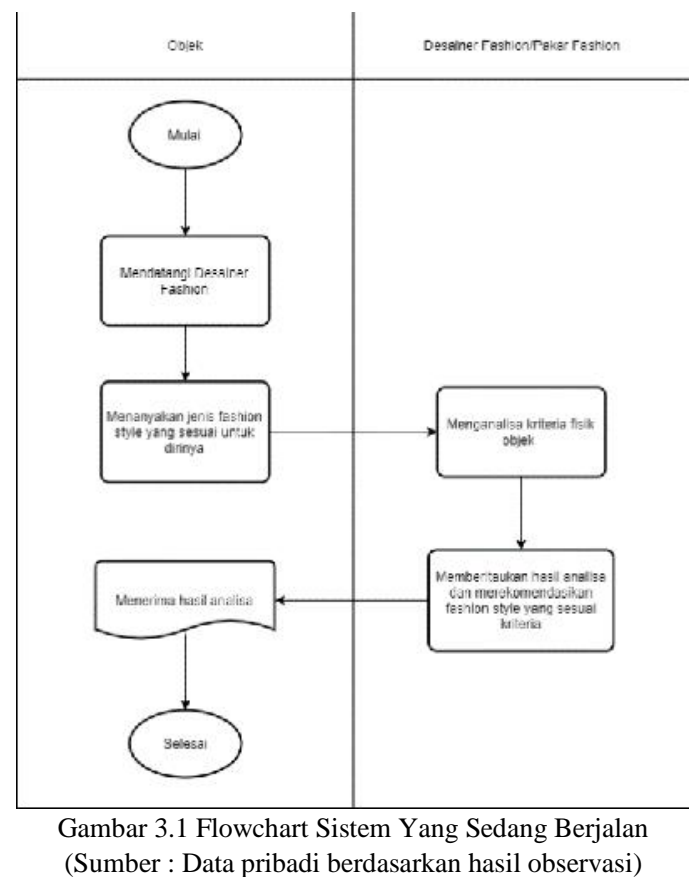

\subsection{Perhitungan Metode Certainty Factor}

Untuk menentukan fashion style yang sesuai dengan kriteria fisik user atau pengguna maka dibutuhkan beberapa kriteria fisik dan nilai bobot setiap kriteria fisik yang didapatkan melalui penelitian, dapat dilihat pada Tabel 3.1

Tabel 3.1 Kriteria Fisik

\begin{tabular}{|c|c|c|c|c|}
\hline $\begin{array}{l}\text { Kode } \\
\text { Kriteria }\end{array}$ & Kriteria Fisik & Cluster & MB & MD \\
\hline E1 & Wajah bulat & Kepala & 0.6 & 0.2 \\
\hline E2 & Wajah oval & Kepala & 0.8 & 0.2 \\
\hline E3 & Wajah kotak & Kepala & 0.2 & 0.8 \\
\hline E4 & Wajah diamond face & Kepala & 0.2 & 0.8 \\
\hline E5 & Rambut keriting & Kepala & 0.8 & 0.4 \\
\hline E6 & Rambut ikal & Kepala & 0.8 & 0.2 \\
\hline E7 & Rambut lurus & Kepala & 1.0 & 0 \\
\hline E8 & Hidung mancung & Kepala & 1.0 & 0 \\
\hline E9 & Hidung pesek & Kepala & 0.2 & 0.6 \\
\hline E10 & Kulit putih & Tubuh & 0.8 & 0.2 \\
\hline E11 & Kulit sawo matang & Tubuh & 0.6 & 0.4 \\
\hline E12 & Kulit hitam & Tubuh & 0.6 & 0.4 \\
\hline E13 & Tinggi badan pendek & Tubuh & 0.6 & 0.4 \\
\hline E14 & Tinggi badan tinggi & Tubuh & 1.0 & 0 \\
\hline E15 & Tubuh kurus & Tubuh & 0.6 & 0.4 \\
\hline E16 & Tubuh ideal & Tubuh & 0.8 & 0 \\
\hline E17 & Tubuh gemuk & Tubuh & 0.2 & 0.8 \\
\hline E18 & Kaki sejajar I & Kaki & 0.8 & 0.2 \\
\hline E19 & Kaki sejajar O & Kaki & 0.4 & 0.6 \\
\hline E20 & Kaki sejajar X & Kaki & 0.2 & 1.0 \\
\hline
\end{tabular}

Untuk data fashion style yang ada pada sistem yang akan dikembangkan dapat dilihat pada Tabel 3.2

Tabel 3.2 Fashion Style

\begin{tabular}{|c|c|}
\hline Kode Fashion & Fashion Style \\
\hline H1 & Chic Style \\
\hline
\end{tabular}




\begin{tabular}{|c|c|}
\hline $\mathrm{H} 2$ & Haute Couture Style \\
\hline $\mathrm{H} 3$ & Edgy Style \\
\hline $\mathrm{H} 4$ & Monochrome Style \\
\hline $\mathrm{H} 5$ & Casual Style \\
\hline $\mathrm{H} 6$ & Classy Style \\
\hline $\mathrm{H} 7$ & Vintage Style \\
\hline $\mathrm{H} 8$ & Retro Style \\
\hline $\mathrm{H} 9$ & Layering Style \\
\hline $\mathrm{H} 10$ & Streetwear Style \\
\hline $\mathrm{H} 11$ & Fashionista Style \\
\hline $\mathrm{H} 12$ & Oversized Style \\
\hline $\mathrm{H} 13$ & $\begin{array}{c}\text { Sophisticated Style } \\
\text { H14 }\end{array}$ \\
\hline Outerwear Style \\
\hline
\end{tabular}

Berikut ini adalah data diagnosa untuk menentukan fashion style berdasarkan kriteria fisik pada sistem, dapat dilihat pada Tabel 3.3

\begin{tabular}{|c|c|c|}
\hline \multicolumn{3}{|c|}{ Tabel 3.3 Diagnosa } \\
\hline No & Fashion Style & Kriteria Fisik \\
\hline \multirow[t]{8}{*}{1} & \multirow[t]{8}{*}{ Chic Style } & - Wajah oval \\
\hline & & - Rambut lurus \\
\hline & & - Hidung mancung \\
\hline & & - Kulit sawo matang \\
\hline & & - Tinggi badan tinggi \\
\hline & & - Tubuh ideal \\
\hline & & - Kaki sejajar I \\
\hline & & - Kaki sejajar X \\
\hline \multirow[t]{3}{*}{2} & \multirow[t]{3}{*}{ Haute Couture Style } & - Wajah oval \\
\hline & & - Wajah kotak \\
\hline & & - Rambut lurus \\
\hline
\end{tabular}

\begin{tabular}{|c|c|c|}
\hline & & \multirow{2}{*}{$\begin{array}{l}\text { - Hidung mancung } \\
\text { - Kulit putih }\end{array}$} \\
\hline & & \\
\hline & & - Tinggi badan tinggi \\
\hline & & - Tubuh ideal \\
\hline & & - Kaki sejajar I \\
\hline 3 & \multirow[t]{7}{*}{ Edgy Style } & - Wajah kotak \\
\hline & & - Rambut keriting \\
\hline & & - Hidung pesek \\
\hline & & - Kulit putih \\
\hline & & - Tinggi badan pendek \\
\hline & & - Tubuh gemuk \\
\hline & & - Kaki sejajar I \\
\hline \multirow[t]{8}{*}{4} & \multirow[t]{8}{*}{ Monochrome Style } & - Wajah oval \\
\hline & & - Wajah kotak \\
\hline & & - Rambut lurus \\
\hline & & - Hidung mancung \\
\hline & & - Kulit sawo matang \\
\hline & & - Tinggi badan tinggi \\
\hline & & - Tubuh kurus \\
\hline & & - Kaki sejajar I \\
\hline \multirow[t]{7}{*}{5} & \multirow[t]{7}{*}{ Casual Style } & - Wajah oval \\
\hline & & - Rambut lurus \\
\hline & & - Hidung mancung \\
\hline & & - Kulit sawo matang \\
\hline & & - Tinggi badan tinggi \\
\hline & & - Tubuh ideal \\
\hline & & - Tubuh gemuk \\
\hline
\end{tabular}




\begin{tabular}{|c|c|c|}
\hline & & - Kaki sejajar I \\
\hline \multirow[t]{8}{*}{6} & \multirow[t]{8}{*}{ Classy Style } & - Wajah bulat \\
\hline & & - Rambut lurus \\
\hline & & - Rambut keriting \\
\hline & & - Hidung mancung \\
\hline & & - Kulit sawo matang \\
\hline & & - Tinggi badan tinggi \\
\hline & & - Tubuh ideal \\
\hline & & - Kaki sejajar O \\
\hline \multirow[t]{7}{*}{7} & \multirow[t]{7}{*}{ Vintage Style } & - Wajah bulat \\
\hline & & - Rambut keriting \\
\hline & & - Hidung pesek \\
\hline & & - Kulit putih \\
\hline & & - Tinggi badan pendek \\
\hline & & - Tubuh kurus \\
\hline & & - Kaki sejajar O \\
\hline \multirow[t]{7}{*}{8} & \multirow[t]{7}{*}{ Retro Style } & - Wajah bulat \\
\hline & & - Rambut keriting \\
\hline & & - Hidung pesek \\
\hline & & - Kulit hitam \\
\hline & & - Tinggi badan pendek \\
\hline & & - Tubuh kurus \\
\hline & & - Kaki sejajar X \\
\hline
\end{tabular}

Berdasarkan Tabel 3.3 Diagnosa maka dibuat beberapa kaidah atau rule antara lain sebagai berikut:

1. IF Wajah Oval AND Rambut Lurus AND Hidung Mancung $\boldsymbol{A N D}$ Kulit Sawo Matang $\boldsymbol{A N D}$ Tinggi Badan Tinggi $\boldsymbol{A N D}$ Tubuh Ideal $\boldsymbol{A N D}$ Kaki Sejajar I $\boldsymbol{O R}$ Kaki Sejajar X THEN Chic Style
2. IF Wajah Oval $\boldsymbol{O R}$ Wajah Kotak $\boldsymbol{A N D}$ Rambut Lurus $\boldsymbol{A N D}$ Hidung Mancung $\boldsymbol{A N D}$ Kulit Putih $\boldsymbol{A N D}$ Tinggi Badan Tinggi $\boldsymbol{A N D}$ Tubuh Ideal $\boldsymbol{A N D}$ Kaki Sejajar I THEN Haute Couture Style

3. IF Wajah Kotak AND Rambut Keriting AND Hidung Pesek $\boldsymbol{A N D}$ Kulit Putih $\boldsymbol{A} \boldsymbol{N D}$ Tinggi Badan Pendek $\boldsymbol{A N D}$ Tubuh Gemuk AND Kaki Sejajar I THEN Edgy Style

4. IF Wajah Oval $\boldsymbol{O R}$ Wajah Kotak $\boldsymbol{A N D}$ Rambut Lurus $\boldsymbol{A N D}$ Hidung Mancung $\boldsymbol{A N D}$ Kulit Sawo Matang $\boldsymbol{A N D}$ Tinggi Badan Tinggi $\boldsymbol{A N D}$ Tubuh Kurus AND Kaki Sejajar I THEN Monochrome Style

5. IF Wajah Oval AND Rambut Lurus AND Hidung Mancung $\boldsymbol{A N D}$ Kulit Sawo Matang $\boldsymbol{A N D}$ Tinggi Badan Tinggi $\boldsymbol{A N D}$ Tubuh Ideal $\boldsymbol{O} \boldsymbol{R}$ Tubuh Gemuk $\boldsymbol{A N D}$ Kaki Sejajar I THEN Casual Style

6. IF Wajah Bulat $\boldsymbol{A N D}$ Rambut Keriting $\boldsymbol{O R}$ Rambut Lurus $\boldsymbol{A N D}$ Hidung Mancung $\boldsymbol{A N D}$ Kulit Sawo Matang $\boldsymbol{A N D}$ Tinggi Badan Tinggi $\boldsymbol{A N D}$ Tubuh Ideal $\boldsymbol{A} \boldsymbol{N D}$ Kaki Sejajar O THEN Classy Style

7. IF Wajah Bulat AND Rambut Keriting AND Hidung Pesek $\boldsymbol{A N D}$ Kulit Putih $\boldsymbol{A N D}$ Tinggi Badan Pendek $\boldsymbol{A N D}$ Tubuh Kurus AND Kaki Sejajar O THEN Vintage Style

8. IF Wajah Bulat $\boldsymbol{A N D}$ Rambut Keriting $\boldsymbol{A N D}$ Hidung Pesek $\boldsymbol{A N D}$ Kulit Hitam $\boldsymbol{A} \boldsymbol{N D}$ Tinggi Badan Pendek $\boldsymbol{A N D}$ Tubuh Kurus AND Kaki Sejajar X THEN Retro Style

9. IF Wajah Kotak $\boldsymbol{A N D}$ Rambut Ikal $\boldsymbol{A} \boldsymbol{N D}$ Hidung Pesek $\boldsymbol{A N D}$ Kulit Hitam $\boldsymbol{A N D}$ Tinggi Badan Pendek $\boldsymbol{A} \boldsymbol{N D}$ Tubuh Gemuk AND Kaki Sejajar O THEN Layering Style

10. IF Wajah Diamond $\boldsymbol{A} \boldsymbol{N D}$ Rambut Keriting $\boldsymbol{A} \boldsymbol{N D}$ Hidung Pesek $\boldsymbol{A} \boldsymbol{N D}$ Kulit Hitam $\boldsymbol{A} \boldsymbol{N D}$ Tinggi Badan Pendek $\boldsymbol{A N D}$ Tubuh Gemuk AND Kaki Sejajar X THEN Streetwear Style

11. IF Wajah Diamond $\boldsymbol{A} \boldsymbol{N D}$ Rambut Ikal $\boldsymbol{A} \boldsymbol{N D}$ Hidung Pesek $\boldsymbol{A N D}$ Kulit Hitam $\boldsymbol{A} \boldsymbol{N D}$ Tinggi Badan Pendek $\boldsymbol{A} \boldsymbol{N D}$ Tubuh Gemuk AND Kaki Sejajar X THEN Fashionista Style

12. IF Wajah Diamond $\boldsymbol{A} \boldsymbol{N D}$ Rambut Ikal $\boldsymbol{A} \boldsymbol{N D}$ Hidung Pesek $\boldsymbol{A N D}$ Kulit Putih $\boldsymbol{A N D}$ Tinggi Badan Pendek $\boldsymbol{A N D}$ Tubuh Kurus AND Kaki Sejajar O THEN Oversized Style

13. IF Wajah Bulat $\boldsymbol{A N D}$ Rambut Ikal $\boldsymbol{A} \boldsymbol{N D}$ Hidung Mancung $\boldsymbol{A N D}$ Kulit Sawo Matang AND Tinggi Badan Tinggi $\boldsymbol{A N D}$ Tubuh Ideal AND Kaki Sejajar X THEN Sophisticated Style

14. IF Wajah Diamond $\boldsymbol{A N D}$ Rambut Ikal AND Hidung Mancung AND Kulit Putih $\boldsymbol{A N D}$ Tinggi Badan Tinggi AND Tubuh Kurus AND Kaki Sejajar O THEN Outerwear Style

\subsection{Perhitungan Data Dengan Metode Certainty Factor}

Langkah pertama objek penelitian diberikan beberapa pertanyaan terkait kriteria fisik dan mengisi nilai keyakinan setiap kriteria fisik yang ada. Nilai bobot keyakinan umumnya seperti pada Tabel 3.4 


\begin{tabular}{|c|c|}
\hline Certainty Term & Nilai Certainty Factor \\
\hline Tidak & 0 \\
\hline Tidak Tau & 0.2 \\
\hline Sedikit Yakin & 0.4 \\
\hline Cukup Yakin & 0.6 \\
\hline Yakin & 0.8 \\
\hline Sangat Yakin & 1 \\
\hline
\end{tabular}

Studi kasus, seorang perempuan berusia 22 tahun dianalisis berdasarkan jawaban objek melalui hasil penelitian memiliki kriteria fisik sebagai berikut, dapat dilihat pada Tabel 3.5

Tabel 3.5 Data Diagnosa Objek Penelitian

\begin{tabular}{|c|c|c|c|c|}
\hline No & Nama & Kriteria Fisik & Jawaban & $\begin{array}{l}\text { CF } \\
\text { User }\end{array}$ \\
\hline 1 & $\begin{array}{l}\text { Arty } \\
\text { Indriani } \\
\text { Danial }\end{array}$ & $\begin{array}{l}\text { - Wajah bulat } \\
\text { - Wajah oval } \\
\text { - Wajah kotak } \\
\text { - Wajah diamond } \\
\text { - Rambut keriting } \\
\text { - Rambut ikal } \\
\text { - Rambut lurus } \\
\text { - Hidung mancung } \\
\text { - Hidung pesek } \\
\text { - Kulit putih } \\
\text { - Kulit sawo matang } \\
\text { - Kulit hitam } \\
\text { Tinggi badan } \\
\text { pendek } \\
\text { - Tinggi badan tinggi } \\
\text { - Tubuh kurus } \\
\text { - Tubuh ideal } \\
\text { - Tubuh gemuk }\end{array}$ & $\begin{array}{l}\text { Ya } \\
\text { Tidak }\end{array}$ & $\begin{array}{l}0.5 \\
0\end{array}$ \\
\hline
\end{tabular}

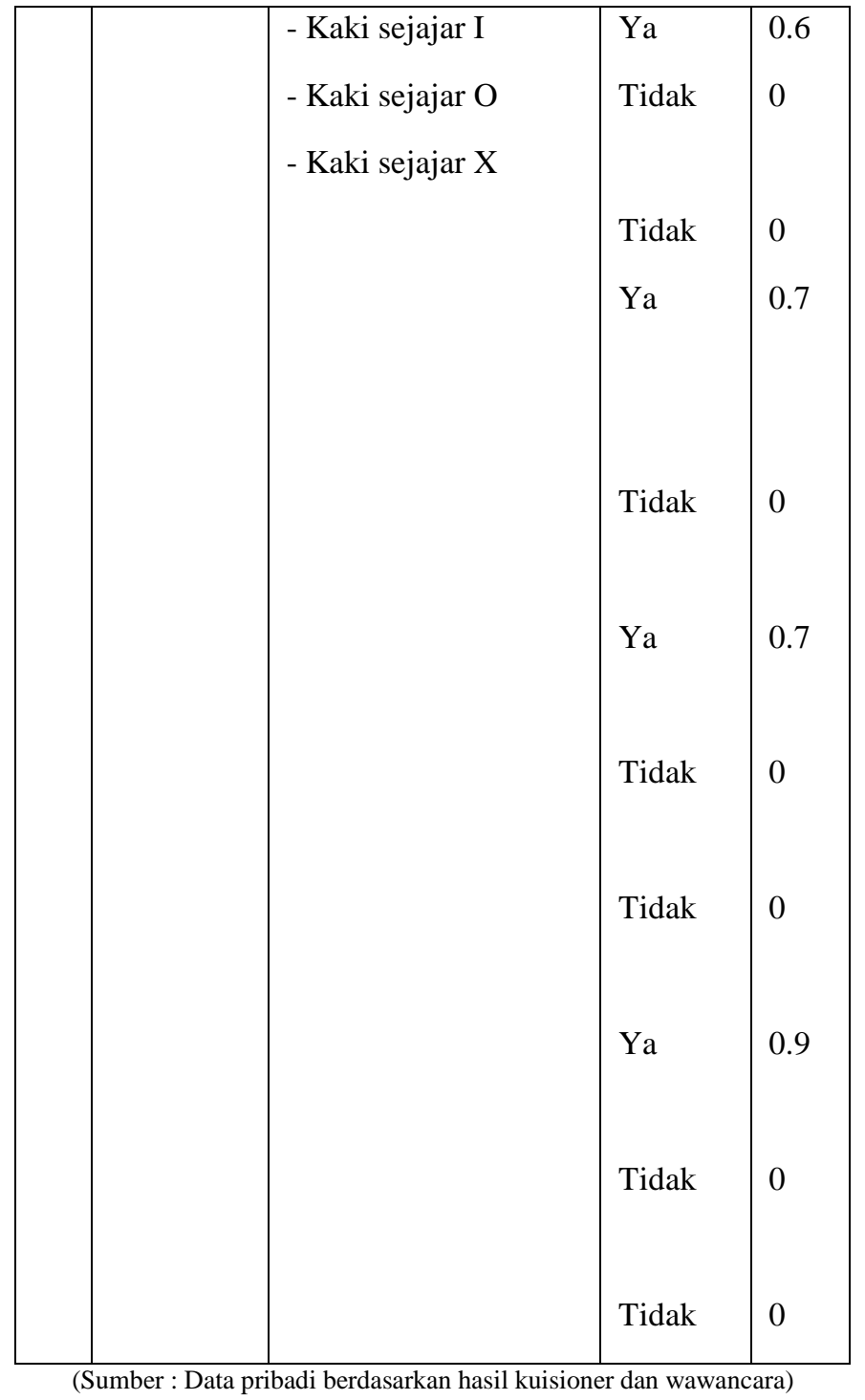

Langkah berikutnya adalah mengambil data rule yang akan digunakan pada perhitungan metode certainty factor. Sebagai contoh diambil salah satu rule dari 14 rule kriteria majemuk yang ada untuk melakukan perhitungan certainty factor yaitu rule diagnosa Haute Couture Style sebagai berikut:

$\boldsymbol{I F}$ Wajah Oval $\boldsymbol{O} \boldsymbol{R}$ Wajah Kotak $\boldsymbol{A N D}$ Rambut Lurus $\boldsymbol{A N D}$ Hidung Mancung $\boldsymbol{A N D}$ Kulit Putih $\boldsymbol{A N D}$ Tinggi Badan Tinggi AND Tubuh Ideal AND Kaki Sejajar I THEN Haute Couture Style.

Langkah berikutnya adalah pemecahan rule dengan kriteria majemuk menjadi rule dengan kriteria tunggal. Sebagai berikut:

IF Wajah Oval THEN Haute Couture Style IF Wajah Kotak THEN Haute Couture Style 
IF Rambut Lurus THEN Haute Couture Style

IF Hidung Mancung THEN Haute Couture Style

IF Kulit Putih THEN Haute Couture Style

IF Tinggi Badan Tinggi THEN Haute Couture Style

IF Tubuh Ideal THEN Haute Couture Style

IF Kaki Sejajar I THEN Haute Couture Style

Langkah selanjutnya adalah menentukan nilai $\mathrm{CF}$ Rule dari setiap kriteria fisik pada rule diagnosa Haute Couture Style. Dapat dilihat pada Tabel 3.6

\begin{tabular}{|c|c|c|c|}
\hline Kode Kriteria & Kriteria & CF User & $\begin{array}{l}\text { CF } \\
\text { Rule } \\
\text { (MB- } \\
\text { MD) }\end{array}$ \\
\hline E2 & - Wajah oval & 0.5 & 0.6 \\
\hline E3 & - Wajah kotak & 0 & -0.6 \\
\hline E7 & - Rambut lurus & 0 & 1 \\
\hline E8 & - Hidung mancung & 0.5 & 1 \\
\hline E10 & - Kulit putih & & \\
\hline E14 & - Tinggi badan tinggi & 0.6 & 0.6 \\
\hline E16 & - Tubuh ideal & 0 & 1 \\
\hline \multirow[t]{3}{*}{ E18 } & - Kaki sejajar I & & \\
\hline & & 0 & 0.8 \\
\hline & & 0.9 & 0.6 \\
\hline
\end{tabular}

(Sumber : Data pribadi berdasarkan hasil kuisioner, observasi dan studi literatur)

Langkah selanjutnya adalah menghitung nilai CF dari setiap kriteria menggunakan persamaan sebagain berikut:

CF $(\mathrm{H}, \mathrm{E})=\mathrm{CF}$ (user) $* \mathrm{CF}$ (rule)

$\mathrm{CF}(\mathrm{H}, \mathrm{E}) 2=0,5 * 0,6=0.3$

$\mathrm{CF}(\mathrm{H}, \mathrm{E}) 3=0 *(-0.6)=0$

$\mathrm{CF}(\mathrm{H}, \mathrm{E}) 7=0 * 1=0$

$\mathrm{CF}(\mathrm{H}, \mathrm{E}) 8=0,5 * 1=0,5$

$\mathrm{CF}(\mathrm{H}, \mathrm{E}) 10=0,6 * 0.6=0,36$

$\mathrm{CF}(\mathrm{H}, \mathrm{E}) 14=0 * 1=0$

$\mathrm{CF}(\mathrm{H}, \mathrm{E}) 16=0 * 0.8=0$

$\mathrm{CF}(\mathrm{H}, \mathrm{E}) 18=0.9 * 0,6=0,54$

Langkah terakhir adalah mengkombinasikan nilai $\mathrm{CF}$ dari setiap kriteria, karena terdapat variabel $\boldsymbol{O R}$ pada rule diagnosa Haute Couture Style maka kriteria fisik yang diantara variabel $\boldsymbol{O R}$ harus dikombinasikan secara terpisah.
Sebagai contoh diambil salah satu kriteria fisik diantara variabel $\boldsymbol{O} \boldsymbol{R}$ yang memiliki nilai bobot keyakinan user lebih besar yaitu Bentuk Wajah Oval. Kombinasi CF (H,E)1 sampai $\mathrm{CF}(\mathrm{H}, \mathrm{E}) 20$ dengan persamaan sebagai berikut:

CFcombine (CF (H,E)1,CF $(\mathrm{H}, \mathrm{E}) 2)=\mathrm{CF}(\mathrm{H}, \mathrm{E}) 1+\mathrm{CF}$ $(\mathrm{H}, \mathrm{E}) 2 *(\mathbf{1}-\mathrm{CF}(\mathrm{H}, \mathrm{E}) \mathbf{1})$

CFcombine $(\mathrm{CF}(\mathrm{H}, \mathrm{E}) 2, \mathrm{CF}(\mathrm{H}, \mathrm{E}) 7)=0,3+0 *(1-0,3)$

$=0,3 \mathrm{CF}$ old 1

CFcombine (CF old1, CF $(\mathrm{H}, \mathrm{E}) 8)=0,3+0,5 *(1-0,3)$

$=0,65 \mathrm{CF}$ old 2

CFcombine (CF old2,CF $(\mathrm{H}, \mathrm{E}) 10)=0,65+0,36 *(1-0,65)$ $=0,776$ CF old 3

CFcombine $(\mathrm{CF}$ old $3, \mathrm{CF}(\mathrm{H}, \mathrm{E}) 14)=0,776+0 *(1-0,776)$

$=0,776 \mathrm{CF}$ old 4

CFcombine (CF old4,CF (H,E) 16) $=0,776+0 *(1-0,776)$

$=0,776 \mathrm{CF}$ old 5

CFcombine $(\mathrm{CF}$ old5, $\mathrm{CF}(\mathrm{H}, \mathrm{E}) 18)=0,776+0,54 *(1-$ $0,776)$

$=0,89696 \mathrm{CF}$ old 6

Berdasarkan hasil perhitungan certainty factor diatas, maka nilai CF untuk diagnosa fashion haute couture style adalah 0,89696 .

Maka dapat dihitung presentase keyakinan dari hasil perhitungan nilai $\mathrm{CF}$ diatas dengan persamaan sebagai berikut:

Presentase Keyakinan = CF old6 $* 100 \%$

$$
=0,89696 * 100 \%
$$

$$
=89,696 \%
$$

Dapat dibulatkan menjadi $89,69 \%$.

Dengan demikian dapat dikatakan bahwa perhitungan certainty factor pada kriteria fashion haute couture style memiliki tingkat presentase keyakinan $\mathbf{8 9 , 6 9 \%}$.

\subsection{Perancangan Sistem}

1. Diagram Use Case

Diagram use case digunakan untuk memodelkan fungsional sistem yang digunakan oleh pengguna sistem. Berikut ini adalah diagram use case untuk aplikasi menentukan fashion style berdasarkan kriteria fisik dengan metode certainty factor dapat dilihat pada Gambar 3.2 


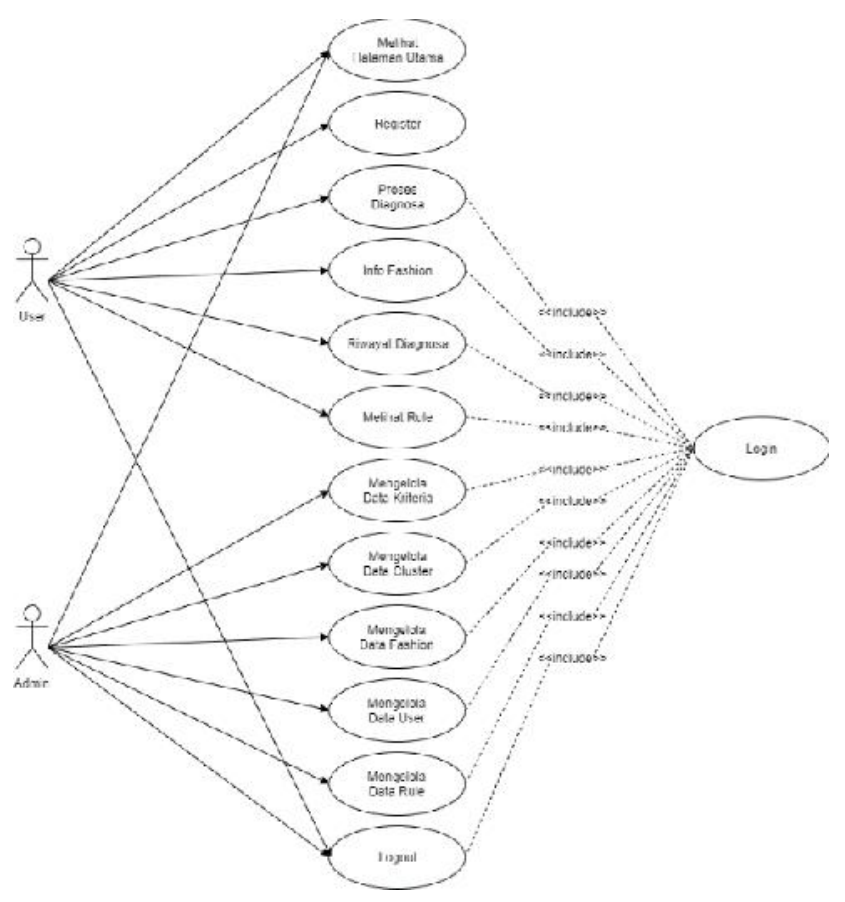

Gambar 3.2 Diagram Use Case

(Sumber : Data pribadi berdasarkan hasil analisis)

\section{Class Diagram}

Class diagram menggambarkan struktur dan deskripsi serta hubungan antar tabel pada perancangan database. Dapat dilihat pada Gambar 3.3

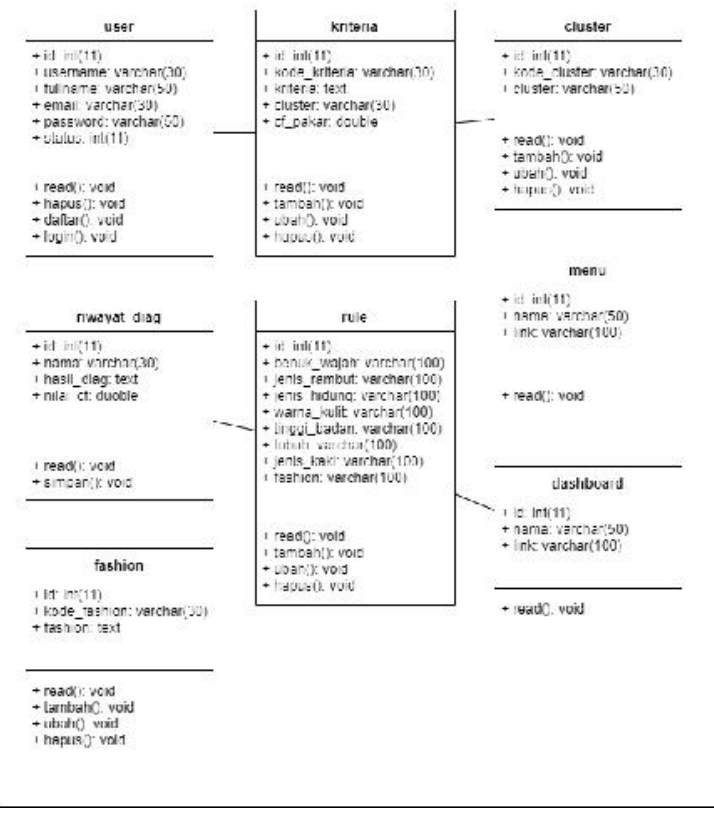

Gambar 3.3 Class Diagram

(Sumber : Data pribadi berdasarkan hasil analisis)

\subsection{Tampilan Sistem Pakar Penentuan Fashion Style}

Berikut ini penjelasan mengenai implementasi program dan pembahasan dari aplikasi menentukan fashion style berdasarkan kriteria fisik dengan metode certainty factor. Tampilan aplikasi dibagi menjadi 2 bagian, yaitu tampilan halaman user dan tampilan halaman admin [8-18].

\subsection{Tampilan Sistem Pakar Penentuan Fashion Style}

Tampilan halaman utama merupakan tampilan awal dari sistem ketika pengunjung pertama kali memasuki aplikasi dan menampilkan menu home dan login. Tampilan halaman utama dapat dilihat pada Gambar 3.4

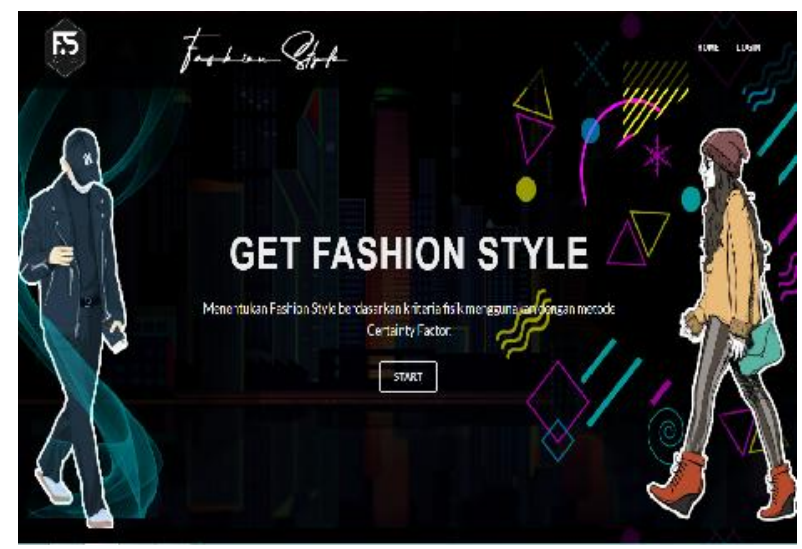

Gambar 3.4 Halaman Utama Sistem (Sumber : Data pribadi berdasarkan hasil perancangan)

\section{KESIMPULAN}

Berdasarkan hasil perancangan aplikasi menentukan fashion style berdasarkan kriteria fisik dengan menggunakan metode certainty factor berbasis web dapat disimpulkan sebagai berikut :

1. Sistem pakar penentuan fashion style ini dapat membantu masyarakat khususnya perempuan berusia 18-30 tahun untuk mengetahui jenis fashion style yang sesuai dengan kriteria fisiknya dan memberikan rekomendasi berupa gambar ilustrasi serta informasi tentang fashion style, aplikasi ini dapat dijadikan sebagai media ilmu pengetahuan mengenai fashion style.

2. Sistem pakar penentuan fashion style ini di rancang dan dapat digunakan untuk menentukan fashion style berdasarkan kriteria fisik manusia dan untuk menabah ilmu pengetahuan mengenai bidang fashion style.

3. Sistem pakar penentuan fashion style ini dapat dijalankan dan di akses oleh semua pengguna internet melalui link address karena sistem yang dijalankan pada aplikasi untuk menentukan fashion style berdasarkan kriteria fisik dengan menggunakan metode certainty factor berbasis web. 
4. Metode Certainty Factor mampu menyesuaikan jenis fashion style dan dapat memberikan rekomendasi fashion style berdasarkan hasil perhitungan yang memiliki tingkat keakuratan cukup tinggi. Sehingga metode ini dapat menyelesaikan permasalahan yang ada dalam bidang fashion style.

\section{REFERENSI}

[1]. Angela Dios, et al. "Buku Ilustrasi 'Fashion \& Style Guide,”. Jurnal Desain Komunikasi Visual. Vol. 7. No. (2). 2018.

[2]. Apip Supiandi, dan Damar Bagja C. "Sistem Pakar Diagnosa Depresi Mahasiswa Akhir dengan Metode Certainty Factor Berbasis Mobile". Jurnal Informatika. Vol. 5. No. (1). 102-111. 2018.

[3]. Dita Syifani, Ardiansyah Dores. "Aplikasi Sistem Rekam Medis di Puskesmas Kelurahan Gunung”. Jurnal Sistem Informasi, Teknologi Informatika dan Komputer. Vol. 9. No. (1). 22-31. 2018.

[4]. Penda Sudarto Hasugian. "Perancangan Website sebagai Media Promosi dan Informasi”. Jurnal Of Informatic Pelita Nusantara. Vol. 3. No. (1). 82-86. 2018.

[5]. Rizky Mandasari. "15 Istilah fashion ini kerap muncul tapi tak semua orang paham artinya" [Online]. Tersedia: https://brilistyle.brilio.net/info/15istilah-fashion-ini-kerap-muncul-tapi-tak-semuaorang-paham-artinya-170510q.html [25 November 2019].

[6]. Sari Iswanti. "Alat Bantu Pengidentifikasi Tingkat Stres Mahasiswa yang Sedang Mengerjakan Tugas Akhir/Skripsi”. Jurnal Informatika UPGRIS. Vol. 4. No. (1). 56-63. 2018.

[7]. VDP Jati. "Karakteristik Fisik Secara Somatoskopi dan Adaptasi Budaya pada Populasi Masyarakat Tengger di Desa Argosari, Kecamatan Senduro, Kabupaten Lumajang”. AntroUnairdotNet. Vol. 6. No. (2). 245-259. 2017.

[8]. Rosalina, Vidila., Mulyanah, Malik A., "Electronic Customer Relationship Management (E-CRM) Modeling on MSMEs Banten", International Journal of Computer Applications (0975 - 8887) Volume 176, October 2017, New York, USA .2017.

[9]. Rosalina, Vidila., Mulyanah, Malik A., Perwitasari P., "Model Electronic Customer Relationship Management (E-CRM) Menggunakan Adaptasi Bahasa Lokal Pada Usaha Mikro Kecil Menengah (UMKM) Banten", Prosiding Seminar Nasional Riset Terapan : SENASSET 2017 ISBN 978-602-736720-3 : 12, November 2017, Serang. 2017.

[10]. Rosalina, Vidila., Malik A., Perwitasari E. "Sosialisasi Manfaat Electronic Customer
Relationship Management (E-CRM) dalam Upaya Meningkatkan Retensi Pelanggan UMKM Cilegon”. Jurnal Pengabdian Masyarakat Wikrama Parahita Vol 1 No 1, November 2017.

[11]. Rosalina, Vidila., Hamdan. "Electronic Customer Relationship Management (E-CRM) Modeling As Efforts to Increase Customer Retention of Micro Small and Medium Enterprises (MSMEs) in Banten". International Conference On Computer Science Engineering and Technology : ICComSET 2018, Tasikmalaya, 27-28 November 2018.

[12]. Rosalina, Vidila., Hamdan, Saefudin. " Mobile Customer Relationship Management (m-CRM) Application Development in MSMEs Indonesia", Journal of Physic : Conference Series Volume 1179, 2019, Published under licence by IOP Publishing Ltd. 2019.

[13]. Rosalina, Vidila, Hamdan, Triayudi A.. "Electronic Customer Relationship Management (E-CRM) Application as Efforts to Increase Customer Retention of Micro Small and Medium Enterprises (MSMEs) in Banten Indonesia" International Journal of Computer Applications - IJCA Volume 182, January 2019, ISSN 0975 - 8887, New York, USA. 2019.

[14]. Fahrudiansyah Tubagus, Vidila Rosalina, "Electronic Customer Relationship Management (E-CRM) Pengelolaan Sampah dalam Upaya Menuju Serang sebagai Smartcity", Prosiding Seminar Nasional Rekayasa Teknologi Informasi SNARTISI Vol 1 (1), Serang, 2018.

[15]. Rosalina V., Munandar Ai, Hidayanto A. N., Santoso H. B., " Citizen Readiness for Adopting Electronic Citizen Relationship Management (e-CiRM) : A Qualitative Exploration", International Conference Islam and Technology (ICONISTECH), 11-12 July 2019 in Bandung. 2019.

[16]. Rosalina V., Munandar Ai, Hidayanto A.N. "Electronic Citizen Relationship Management (eCiRM) Modeling Towards Serang As a Smart City". International Journal of Computer Applications (0975 - 8887) Volume 175, October 2020.

[17]. Rosalina V., Munandar Ai, Hidayanto A.N., Santoso H.B. "Measuring Citizen Readiness To Adopt Electronic Citizen Relationship Management (ECiRM) Using Technology Readiness Index (TRI)". Journal of Theoretical and Applied Information Technology Vol.98. No 21. 15th November 2020.

[18]. Malik D, Rosalina V. Sistem Pemesanan Makanan Tradisional Berbasis Android Menggunakan Metode Haversine Formula. JSiI Volume 6 No 1. 2019. 